\title{
Water effect on the rocks and mine roadways stability
}

\author{
Olena Slashchova ${ }^{1, *}$ \\ ${ }^{1}$ Institute of Geotechnical Mechanics named by N. Poljakov of National Academy of Sciences of \\ Ukraine, 49005, Dnipro, Simferopolska Str., 2a, Ukraine
}

\begin{abstract}
The article is devoted to solving of a live scientific problem of improving methods for predicting stability of mine roadways under mining-and-geological conditions of the rock watering. Specific effect of water on the rock strength properties was investigated. The generalized correlation dependences of the strength reduction of sandstones, mudstones and siltstones at their saturation with water relatively to their initial strength in natural state were obtained. By method of mathematical modeling, regularity of changes in the stress-strain state of the rock massif depending on rate of preparatory roadway watering were established and confirmed by the mine observations. The correlations were proposed for calculating probable water inflows into the mine roadways basing on the assessment of volume of broken elements in the geomechanical model, parameters of open porosity and fracturing. It is stated that implementation of a set of measures aimed at reducing water flows into the mine roadway improves its stability due to the smaller size of inelastic deformation zones in the walls and roof of the mine roadway in the stationary abutmentpressure zone, reduced contours of the mine roadway deformation, and decreased rate of horizontal and vertical convergence.
\end{abstract}

\section{Introduction}

Today, preparatory roadways are mined in the rocks of medium and low strength. In the active mine roadways, effect of underground and technical waters on the rock massif stability is often ignored. At the same time, clay rocks, even in the drained state, are characterized by relatively weak strength, and, under the moisture effect, can completely lose their bearing capacity. Numerous visual observations and instrumental measurements of the displacements of preparatory roadway contour in the coal mines [1,2] show that stability of the mine roadways is significantly reduced at presence of the water-saturated clay rocks. In this case, sudden roof fall and caving, as well as intensive floor rising occur in the mine roadways.

There are two main reasons for the increase of moisture content in clay in the mine roadway floor and roof. The first reason is seepage of water from aquifers along the fracture systems through the rock massif disturbed by mining operations. These cracks are

\footnotetext{
*Corresponding author: OASlashchova@nas.gov.ua
} 
developed around the goafs at inelastic deformation of rocks [3-5]. The second reason for the rock watering is penetration of water into the mine roadways during technological processes with the use of technical liquids in significantly great volumes. In particular, a great amount of water flows into the roadway floor at the borehole drilling, plugging and concreting and during the anti-dust irrigation. Ignoring of the rock watering factor leads to significant economic losses, since hydrogeological processes contribute to intensive uncontrolled deformation of preparatory roadways. Therefore, prediction of changes in the stress-strain state of the water-saturated rock massif and assessment of expected water inflows into the mine roadways is an important scientific problem, and its solution will allow timely undertaking proper measures in order to improve stability of the mine objects.

\section{Methods}

Analysis of experimental data on assessing state of water-saturated rock massif; statistical processing of laboratory research results on the strength properties of rock samples; mathematical modeling of the rock massif stress-strain state by the finite element method; mine studies of deformations of water-saturated rocks.

\section{Results and discussion}

\subsection{Evaluation of the strength properties of water-saturated rocks}

Since it is impossible to reproduce the whole complex of factors affecting the rock deformations in a single model of geomechanical processes, therefore, it is necessary to choose the most important parameters. In the first place, it is physical-mechanical properties of the rocks and effect of water saturation on them. Since mudstones and weak siltstones almost completely get soaked in water for 20 days, and sandstone strength is reduced by about 1.5-2.0 times [6], therefore, presence of water in the pores of rocks in an amount close to water saturation drastically changes their behavior in the rock massif. In addition to the rock strength reduction when soluble minerals are washed-out from them, water saturation changes nature of the bonds between the particles, and, in case of the rock deformations, cohesive forces between the rock blocks and layers are reduced.

Three thousand one hundred twenty (3120) rock samples taken from the Western Donbas were studied and tested in laboratory of the Institute of Geotechnical Mechanics, and the obtained results were statistically processed. The rock samples were studied at their saturation with the distilled water, since the so-called "mine water", even taken from different roadways of one and the same mine, features greatly different mineralization. Besides, content of dissolved acids and alkalis in the mine water drastically differs, so it is permissible to use it for analyzing only when solving specific problems for one concrete roadway, or horizon, or, less often, mine. In case of hard sandstone and limestone, strength of water-saturated rocks relatively to their initial strength in their natural state decreases according to the following correlation dependence:

$$
\sigma_{e}^{w}=1.92+0.79 \sigma_{e}, \quad R=0.67,
$$

where $\sigma_{e}{ }^{w}$ is ultimate strength of rocks in their water-saturated state, MPa; $\sigma_{e}$ is ultimate strength of rocks in their natural state, $\mathrm{MPa} ; R$ is coefficient of variation.

Many of the clay rocks samples got completely soaked, therefore, the residual strength of these samples at water-saturation is equal to the strength of the destroyed rocks for the closed volume of the rock massif $\sigma_{e} / 3$ [7], then, the generalized correlation dependence for 
the mudstones and siltstones is written in the following way:

$$
\sigma_{e}^{w}=-2.5+0.67 \sigma_{e}, R=0.76 .
$$

When assessing probability of water seeping through the hardly-permeable formations, it should be borne in mind that the determining factor for formation of the rock massif permeability is its fracturing. The highest permeability is observed in zones of rock rupturing failure, where crack opening increases under the effect of winning operations. In such conditions, forecast of the rock pressure manifestations can be based on geomechanical models, which determine stage of main cracks developing.

For the soils, it is established that, depending on depth, their saturation $W$ with water takes place in accordance with hyperbolic regularity, while their density $\rho$ first increases and then decreases by parabolic dependence (Fig. 1), which, in this case, is associated with the soil subsidence and compaction in the upper clayey layer.

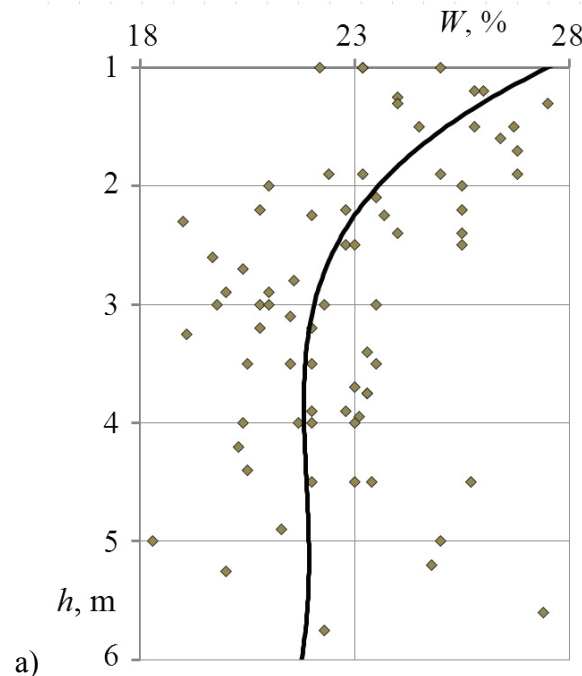

b)

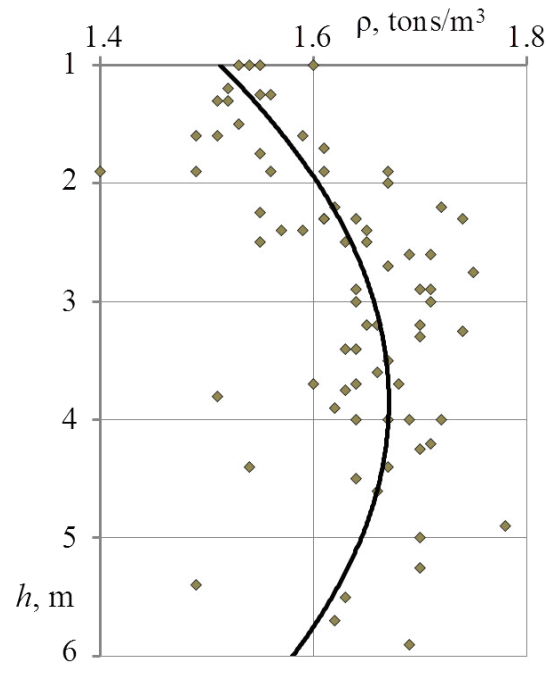

Fig. 1. Dependences of change of relative humidity $W$ (a) and density $\rho($ b) of the soil with the depth during its long-term watering.

\subsection{Modeling of water-saturated rock massif}

Rock massif is a complex structure with pronounced layering and plasticity properties, which present certain difficulty for describing mechanical processes of its deformation. Complexity and multifactor nature of such description requires using of elastoplastic geomechanical models, which can be realized with the help of modern computer technologies based on combination of continuum mechanics methods (solutions are obtained by the finite element method [8]) and theory of limiting states of rocks (is implemented by method of initial strains [7]) subject to discrete analogs of the law of energy conservation for each element separately and the design scheme as a whole. Such approach to solving problems of estimating the stress-strain state of the water-saturated rock massif was implemented in the computer system "GEO-RS ${ }^{\Theta}$ ", developed by the Institute of Geotechnical Mechanics with participation of the author of this paper.

Changes in the rock massif stressed state during its watering were studied on the example of operation of drift 535, coal seam $C_{5}$, in the "Samarska" Mine. Data given by the geological department of the Mine and the established correlation relations (1) and (2) were used as initial data. Despite the small depth of the coal seam bedding $(h=130 \mathrm{~m})$, the 
mining and geological conditions for its development are complex. Roof and floor of the coal seam are presented by mudstones and siltstones with compressive strength $\sigma_{e}=10$ $20 \mathrm{MPa}$. In the immediate floor, weak siltstones $\left(\sigma_{e}=11.8-15.0 \mathrm{MPa}\right)$ occur. At water saturation, the rocks are very unstable and prone to sudden fall. Coal strength is $\sigma_{e} \sim 40 \mathrm{MPa}$. Water-saturated sandstone $\left(\sigma_{e}=11-14 \mathrm{MPa}\right)$ occurs zonally in the roof. The coal seam has a complex hypsometry, distance from the floor to the coal seam changes along the drift length within $\sim 0.6-1.6 \mathrm{~m}$.

In order to determine water saturation effect on the rock pressure manifestations and stability of preparatory roadway, the calculations were performed for water-saturated and dry rocks. Analysis of distribution of maximum principal stresses (Fig. 2, a) showed that stresses at the ends of the coal seam were $(2.1-3.6) \gamma h\left(\gamma\right.$ is volume weight of rocks, $\mathrm{t} / \mathrm{m}^{3} ; h$ is depth, $\mathrm{m}$ ). Due to the fact that the coal seam is $\sim 2-3$ times harder than the lateral rocks, the roof rocks and the coal seam floor are intensively pressed out into the roadway in the watering zones. And, on the contrary, roadway floor is unloaded from stresses. These are signs of existing deformations and floor rising.

As it is shown in Figure 2, b, maximum changes in the rock massif stress at their water saturation occur in extremely stressed rocks of immediate and main roof above the ends of the coal seam to the height of up to $14 \mathrm{~m}$, and also in the roadway wall in the area of abutment pressure at a distance of $\approx 17 \mathrm{~m}$. As a result of intensification of the watersaturated rock massif deformations, maximum principal stresses in the roadway wall from the side of the coal pillar and over the goaf are decreased by $0.3-1.1 \mathrm{MPa}$. On the contrary, stresses of the overlying rocks are increased by 0.1-0.4 MPa. These negative effects of watering lead to the intensive development of zone with inelastic deformations.

Analysis of breakdown zones allows determining the water-seepage paths and volumes of probable water inflows including volumes of aquifers and water accumulation zones. If no hydrogeological data are available, it is proposed to solve the problem on determining the water seepage volume in two stages: first, to determine zones of broken elements by solving the geomechanical problem, and then to calculate potential water inflows.

Water volumes are calculated by total area of the broken elements in the model and by coefficient of loosening or volume porosity of the rocks, which is average for the zone under the study. In the program for geomechanical calculations area under the study is divided into a grid of triangular elements. Let's assume that breakdown zones consist of triangular elements, in which one, two or three bonds have broken. For any of the three points $A\left(x_{1}, y_{1}\right), B\left(x_{2}, y_{2}\right), C\left(x_{3}, y_{3}\right)$ area of triangular element $S_{A B C}$ is calculated by the known formula:

$$
S_{A B C}= \pm \frac{1}{2}\left[\left(x_{2}-x_{1}\right)\left(y_{3}-y_{1}\right)-\left(x_{3}-x_{1}\right)\left(y_{2}-y_{1}\right)\right], \mathrm{m}^{2} .
$$

In the formula, sign "+" means that the expression is positive, and sign "-" means that the expression is negative. Value of the zone area is always positive. Area of the loosing zone $S_{z}$ is equal to sum of $n$ areas of the broken elements in the model:

$$
S_{z}=\sum_{i=1}^{n}\left|S_{i}\right|, \mathrm{m}^{2}
$$

If it is necessary to calculate breakdown zones with several sections, then supposed volume of water accumulation is equal to volume of the water-seepage zone multiplied by coefficient, which characterizes the rock open porosity and fracture $m_{0}$ :

$$
V_{w}=V_{z} m_{0}=\frac{\sum_{i=1}^{n}\left|S_{i}\right|+2 \sum_{i=1}^{m}\left|S_{i}\right|+\ldots+\sum_{i=1}^{k}\left|S_{i}\right|}{2} \times L_{z} m_{0}, \mathrm{~m}^{3},
$$


where $V_{w}$ and $V_{z}$ are volumes of water and water-saturated zone, $\mathrm{m}^{3} ; m_{0}$ is coefficient of open porosity, in rel. unit; $L_{\mathrm{z}}$ is length of the zone along the mine roadway, $\mathrm{m}$.

a)

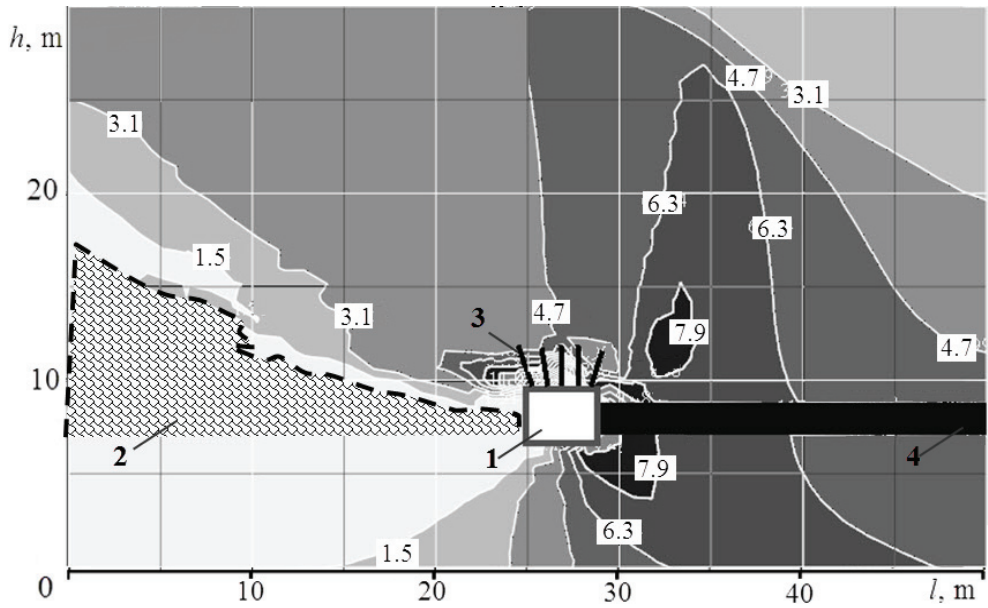

b)

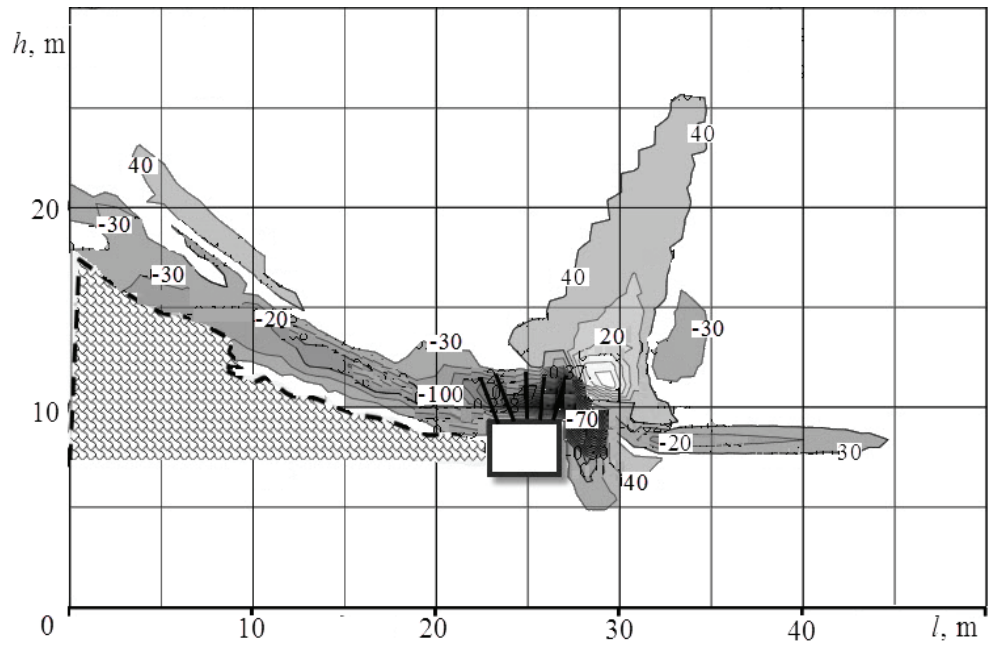

Fig. 2. Regularity of changes in the stressed state of water-saturated rock massif around the drift 535, coal seam $C_{5}$, in the "Samarska" Mine: a - distribution of maximum principal stresses around the drift, MPa; $b$ - zones where stress-strain state of the rock massif changes at its watering (numerals show difference between maximum principal stresses when physical and mechanical properties of water-saturated and drained rocks are considered), $\mathrm{kPa} ; 1$ - mine roadway; 2 - mined-out space; 3 roof bolting system; 4 - coal seam.

In accordance with obtained results on determining zones of the rock massif loosing and breakdown, volumes of probable water inflows into the mine roadways are calculated by the known methods and instructions [1,2]. Based on these data, changes in the stress-strain state of the rock massif and expected water inflows are predicted, and measures are developed for improving stability of the mine objects.

\subsection{Mine research of water-saturated rock deformations}

In order to clarify and verify the calculated data, visual observations and measurements were carried out in the drift 535, coal seam $\mathrm{C}_{5}$, in the "Samarska" Mine [9]. The 
observations showed that most of the rock falls were confined to the watering zones. For example, in the area of the stake 62 (at a distance of $620 \mathrm{~m}$ from the main drifts), water occurs, and host rocks in the roadway walls get soaked resulting in long longitudinal cracks formed in upper corners of the drift (Fig. 3), while water-saturated roof of the mine roadway is warped, exfoliates (Fig. 3, a) and, in some locations, falls (Fig. 3, b).

a)
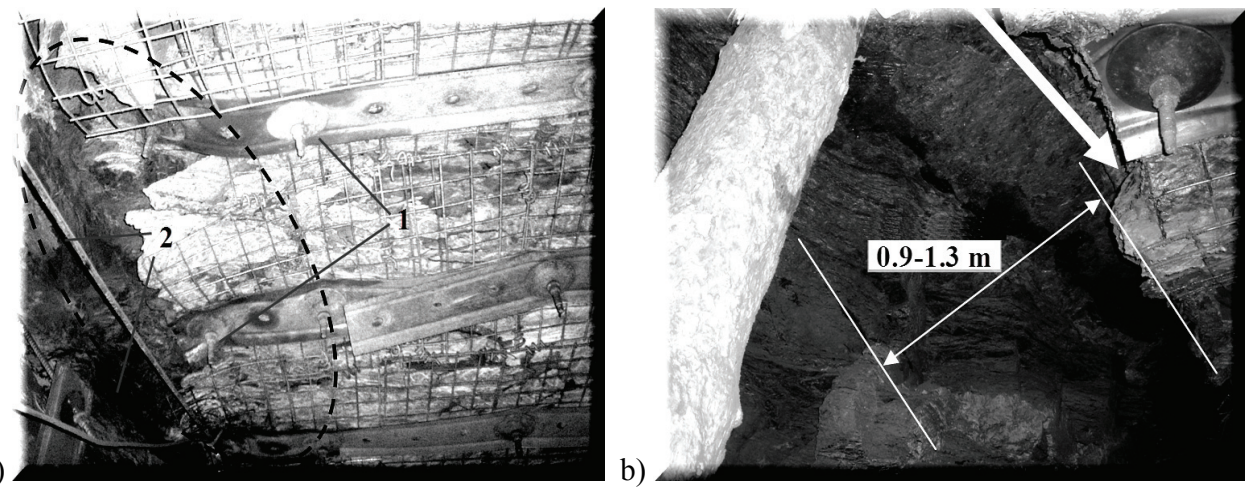

Fig. 3. Rock pressure manifestations at the rock water saturation: a - destruction of the upper corners in the mine roadway (section between 640-670 meters of the drift); b - lateral pressing of watersaturated rocks and falls of the mine roadway walls (sections at $360 \mathrm{~m}$ and $736 \mathrm{~m}$ of the drift); 1 roof bolting system; 2 - falls zone.

According to the results of the mine observations and calculations by the finite element method, nature of deformation of water-saturated rocks in the roof, walls and floor of the mine roadway was determined (Fig. 4). It is established that intense deformations starts in the drift walls and manifest themselves in the form of weak rock slips in the coal seam roof and floor. The most dangerous areas are the upper lateral corners of the mine roadway, which are prone to falls under the effect of water, when the roof bolting system loses its bearing capacity. Such manifestations of rock pressure are reliably predicted by analytical method and are verified by data of mine experiments, making it possible to undertake in advance additional measures for proper supporting the mine roadways.

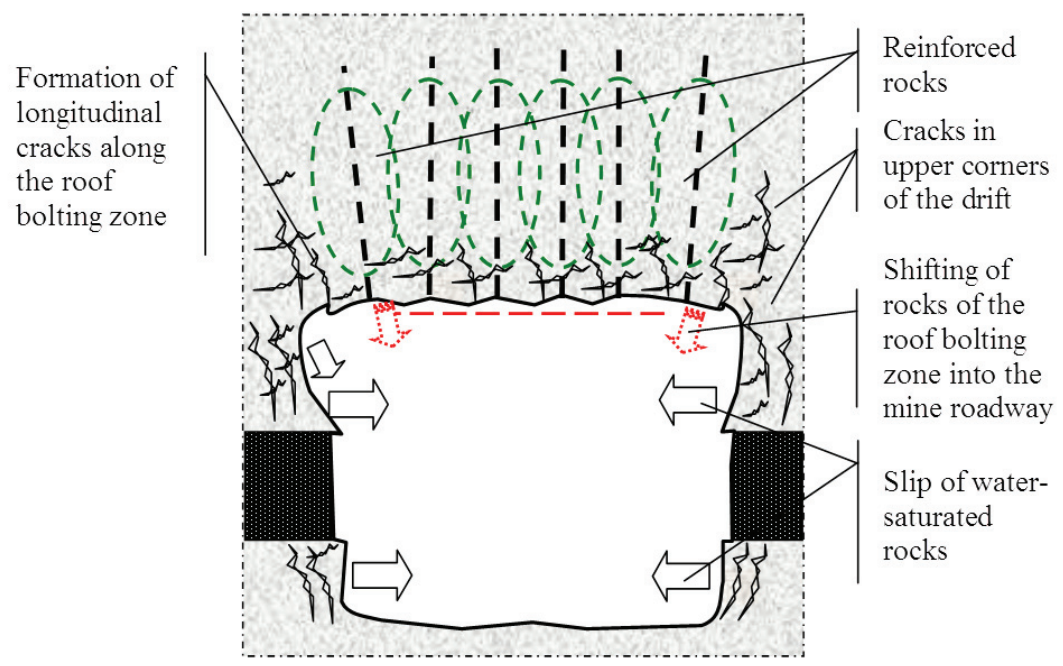

Fig. 4. Manifestations of water-saturated rock deformations in the drift 535 , coal seam $C_{5}$, in the "Samarska" Mine, reproduced in accordance with results of calculations and mine observations. 


\section{Conclusions}

As a result of the research, specific effect of water on the rock strength properties was determined. The generalized correlation dependences of strength reduction of sandstones, mudstones and siltstones at their saturation with water relatively to their initial strength in natural state were obtained. The correlations were proposed for calculating probable water inflows into the mine roadways basing on the assessment of volume of broken elements in the geomechanical model, parameters of open porosity and fracturing. Regularity of changing of the rock-massif stress-strain state depending on rate of preparatory roadway watering were established, which allowed, for the conditions of the "Samarska" Mine, to determine degree of effect of water saturation of the rocks on their stress-strain state and manifestations of rock pressure in the preparatory mine roadways. On the basis of mathematical modeling, it is established that implementation of a set of measures aimed at reducing water flows into the mine roadway improves its stability, namely: it reduces area of inelastic deformation zone in the walls and roof of the mine roadway in zone of stationary abutment pressure, diminishes deformation of the roadway contour and decreases rate of horizontal and vertical convergence.

\section{References}

1. Ikonnikov, M.YU., Ikonnikov, YU.R., Slashcheva, Ye.A., Slashchov, I.M., Yalanskiy, A.O. (2015). Mathematical modeling in solving problems of evaluating the efficacy and safety of mining operations, Dnipropetrovsk: Natsionalnyy gornyy universitet

2. Slashchova, O.A. (2007). The elaboration of the methodic for the express-estimation the stress-strained state of rock mass around the geotechnical installation, Candidate of Technical Sciences Thesis, Institute of Geotechnical Mechanics named by N. Poljakov of National Academy of Sciences of Ukraine, Dnipropetrovsk

3. Tang, C.A., Tham, L.G., Lee, P.K., Yang, T.H., Li, L.C. (2002). Coupled analysis of flow, stress and damage (FSD) in rock failure, International Journal of Rock Mechanics \& Mining Sciences, 39, 477-489

4. Slashchov, I.N., Slashchova, O.A. (2016). Study of caving zone formation in the rock massif at mining adjacent panels in the mines, Geotekhnicheskaya Mekhanika, 128, 179191

5. Krukovskaya, V.V., Krukovskiy, A.P., Vinogradov, Y.A. (2015). Study of water inflow in mine workings with anchors, Geotekhnicheskaya Mekhanika, 120, 182-193

6. Yalanskiy, A.A., Sapunova, I.O., Slashchev, A.I., Novikov, L.A. (2014). Justification of the initial parameters for geomechanical processes modeling in problems of safety assessment of mine workings maintenance", Geotekhnicheskaya Mekhanika, 119, 282295

7. Fadeyev, A.B. (1987). The finite element method in geomechanics. Moskva: Nedra

8. Gallager, R. (1984). Finite Element Analysis. Fundamentals. Moskva: Nauka

9. Slashchov, I.M. (2012). Mining research of systems maintenance stability coal heading in easily cave rock of Western Donbass, Geotekhnicheskaya Mekhanika, 97, 177-185 